\title{
Genetic Diversity Analysis in Extra Early Pigeonpea [Cajanus cajan (L.)] Genotypes using SSR Markers
}

\author{
V. Thirumala Rao, Y. Hari, P. Jagan Mohan Rao, C.V. Sameer Kumar, K. Manasa
}

$10.18805 / L R-4682$

\begin{abstract}
Background: The present study aims at assessment of genetic diversity in 43 extra early pigeonpea genotypes with 41 simple sequence repeat markers.

Methods: In the present investigation, 41 HASSR markers were used to assess the genetic diversity. Similarity matrices were utilized to construct the unweighted pair group method with Arithmetic average dendrogram using NTSYs PC software.

Result: Out of 41 HASSR markers, 21 markers were showed distinct banding pattern, while 11 markers were showed monomorphic banding pattern and remaining 9 markers showed no banding pattern or not amplified. Cluster analysis done using HASSR markers revealed that ICPL87119 was found to be the most diverse. This genotype also found to be resistant to wilt. Based on similarity coefficients and cluster analysis genotypes ICPL87119, ICPL84031, ICPL88014, ICPL161, ICPL87091 and CORG9701 were genetically more distant from other genotypes studied and these varieties can be used for their desirable characteristics in breeding programs for pigeonpea improvement.
\end{abstract}

Key words: Correlation, Genetic diversity, Pigeonpea, SSR markers.

\section{INTRODUCTION}

Pigeonpea is an often cross-pollinated diploid $(2 \mathrm{n}=2 \mathrm{X}=22)$ crop with 833.07 Mb genome size (Varshney et al. 2012a). Pigeonpea plays an important role in sustainable agriculture, because of its multiple usages in food, fodder, soil conservation, crop-livestock integrated systems, reclaiming of degraded pastures, symbiotic nitrogen fixation and has an important role in vegetarian diet in developing countries by ensuring high supply of vitamin B carotene, ascorbic acid and rich protein (22\%) (Varshney et al. 2013). Desirable level of productivity in pigeonpea can be exploited by selecting the existing variability among indigenous germplasm of pigeonpea. However, to attain further breakthrough in increasing yield and improving stability in future cultivars, new variability needs to be tapped and incorporated into cultivars. Using crop wild relatives in breeding programme is a long and laborious process that is typically much more difficult than breeding with cultivated crop varieties. Many plant breeders avoid the use of crop wild relatives for this reason. The first step towards using crop wild relatives in breeding is prebreeding, an essential component for this purpose 43 extra early genotypes are utilized in this research work.

Assessment of genetic diversity has traditionally been made through morphological characters that are often limited in number, have complex inheritance and vulnerable to environmental conditions. DNA marker overcome this ill effect as they are abundant in nature, stable and not influenced by environmental fluctuations. Among the DNA markers, simple sequence repeat (SSR) or microsatellite marker is one of the most useful genetic marker systems that use PCR technique to identify differences in
Regional Agricultural Research Station, Professor Jayashakar Telangana State Agricultural University, Warangal-506 007 Hyderabad, Telangana, India.

Corresponding Author: V. Thirumala Rao, Regional Agricultural Research Station, Professor Jayashakar Telangana State Agricultural University, Warangal-506 007, Hyderabad, Telangana, India. Email: thirugene9@yahoo.com

How to cite this article: Rao, V.T., Hari, Y., Rao, P.J.M., Kumar C.V.S. and Manasa, K. (2022). Genetic Diversity Analysis in Extra Early Pigeonpea [Cajanus cajan (L.)] Genotypes using SSR Markers. Legume Research. DOI: 10.18805/LR-4682.

Submitted: 01-06-2021 Accepted: 04-12-2021 Online: 20-01-2022

microsatellite repeat units. SSR markers are widely used because of its co-dominant, multi allelic, high polymorphism, reproducibility, abundant informativeness, convenience of assay by PCR and distribution throughout the genome, independent of environments, independent of tissue effects and providing more precise characterization of genotypes and measurement of genetic relationships than other markers (Gupta and Varshney, 2000; Hari et al. 2017). SSRs with $\geq 20$ nucleotides and $<20$ nucleotides are referred to as Class I (hypervariable) and Class II, respectively. The significance of hypervariable SSRs in pigeonpea has been established owing to their ease of scoring in simple agarose gel (Bohra et al. 2017). Keeping these points in view, the present investigation was carried out with an objective of understanding the genetic diversity among 43 pigeonpea accessions using hyper variable SSR markers. 


\section{MATERIALS AND METHODS} Collection of plant material

A set of 43 pigeonpea genotypes were obtained from ICRISAT, Patancheru and these genotypes were raised during 2016-17 following standard Agronomic Practices at Regional Agricultural Research Station, Waragal, PJTSAU, Telangana. Leaf samples were collected from all the genotypes at 30 Days after sowing (DAS) for DNA isolation (Table 1).

\section{DNA isolation and PCR analysis}

Genomic DNA from leaf samples was isolated by following the standard protocol as per the procedure described by Murray and Thompson (1986), with few modifications. Final concentration of $30 \mathrm{ng} / \mu \mathrm{l}$ of genomic DNA was used for PCR

Table 1: List of pigeonpea genotypes and their characteristics.

\begin{tabular}{|c|c|c|c|c|c|}
\hline Variety & Plant growth habit & Leaf shape & Flower colour & Days to $50 \%$ flower & Seed colour \\
\hline ICPL-87119 & Indeterminate & Ablong & Yellow & 120 Days & Red \\
\hline UPAS-120 & Indeterminate & Ablong & Yellow & 91 Days & Red \\
\hline ICPL 11263 & Determinate & Ablong & Yellow & 56 Days & Red \\
\hline ICPL11255 & Determinate & Ablong & Yellow & 56 Days & Red \\
\hline ICPL11253 & Determinate & Ablong & Yellow & 58 Days & Red \\
\hline ICPL11256 & Determinate & Ablong & Yellow & 58 Days & Red \\
\hline ICPL11259 & Determinate & Ablong & Yellow & 56 Days & Red \\
\hline ICPL20338 & Determinate & Ablong & Yellow & 58 Days & Red \\
\hline ICPL20340 & Determinate & Ablong & Yellow & 61 Days & Red \\
\hline ICPL11251 & Determinate & Ablong & Yellow & 62 Days & Red \\
\hline ICPL11258 & Determinate & Ablong & Yellow & 68 Days & Red \\
\hline ICPL11260 & Determinate & Ablong & Yellow & 58 Days & Red \\
\hline ICPL11265 & Determinate & Narrowly ablong & Yellow & 58 Days & Red \\
\hline ICPL11254 & Determinate & Ablong & Light yellow & 58 Days & Red \\
\hline ICPL11274 & Determinate & Ablong & Yellow & 59 Days & Red \\
\hline ICPL11276 & Indeterminate & Ablong & Yellow & 59 Days & Red \\
\hline ICPL11298 & Indeterminate & Ablong & Yellow & 59 Days & Red \\
\hline ICPL11318 & Indeterminate & Ablong & Yellow & 70 Days & Red \\
\hline ICPL11300 & Indeterminate & Narrow & Yellow & 70 Days & Red \\
\hline ICPL11326 & Indeterminate & Narrowly ablong & Yellow & 76 Days & Red \\
\hline ICPL11279 & Indeterminate & ablong & Yellow & 76 Days & Red \\
\hline ICPL11285 & Indeterminate & Ablong & Yellow & 73 Days & Red \\
\hline ICPL11242 & Indeterminate & Narrow & Yellow & 71 Days & Red \\
\hline ICPL11292 & Indeterminate & Ablong & Yellow & 77 Days & Red \\
\hline ICPL11245 & Indeterminate & Narrow & Yellow & 63 Days & Red \\
\hline ICPL20333 & Indeterminate & Narrowly ablong & Yellow & 63 Days & Red \\
\hline ICPL11324 & Indeterminate & Ablong & Yellow & 63 Days & Red \\
\hline ICPL20335 & Indeterminate & Narrow & Yellow & 71 Days & Red \\
\hline ICPL20329 & Indeterminate & Ablong & Yellow & 70 Days & Red \\
\hline ICPL20325 & Indeterminate & Ablong & Yellow & 71 Days & Red \\
\hline ICPL20328 & Indeterminate & Ablong & Yellow & 67 Days & Red \\
\hline ICPL11313 & Indeterminate & Narrowly ablong & Yellow & 75 Days & Red \\
\hline ICPL11333 & Indeterminate & Narrow & Yellow & 75 Days & Red \\
\hline ICPL11299 & Indeterminate & Narrow & Yellow & 67 Days & Red \\
\hline ICPL11306 & Indeterminate & Ablong & Yellow & 64 Days & Red \\
\hline ICPL11303 & Indeterminate & Ablong & Yellow & 75 Days & Red \\
\hline ICPL87 & Determinate & Ablong & Yellow & 75 Days & Red \\
\hline ICPL88039 & Indeterminate & Narrowly ablong & Yellow & 100 Days & Red \\
\hline ICPL84031 & Determinate & Ablong & Yellow & 106 Days & Red \\
\hline ICPL88034 & Indeterminate & Narrow & Yellow & 98 Days & Red \\
\hline ICPL161 & Indeterminate & Narrow & Yellow & 106 Days & Red \\
\hline ICPL87091 & Determinate & Ablong & Red & 100 Days & White \\
\hline CORG-9701 & Indeterminate & Ablong & Yellow & 92 Days & Red \\
\hline
\end{tabular}


(Eppendorf) amplification. PCR was performed using $1 \mathrm{U}$ of Taq DNA polymerase (Fermentas, Lithuania) and 1x PCR buffer (Genei, India) in 10- $\mu$ r reaction volume with a thermal profile of $94^{\circ} \mathrm{C}$ for $5 \mathrm{~min}$ (initial denaturation), followed by 35 cycles of denaturation at $94^{\circ} \mathrm{C}$ for 1 minute, annealing temperature (Table 2) for $1 \mathrm{~min}$, extension at $72^{\circ} \mathrm{C}$ for $2 \mathrm{~min}$ and a final extension of $7 \mathrm{~min}$ at $72^{\circ} \mathrm{C}$. The amplified products were electrophoretically resolved on $4 \%$ Seakem LE $®$ Agarose (Lonza, USA), containing $0.5 \mathrm{mg} / \mathrm{ml}$ of ethidium bromide in 0.5x TBE buffer and visualized under UV.

\section{Data analysis}

Allele number was given and scored according to its presence or absence, based on difference in molecular weight. Only the clear and unambiguous bands were scored. 41 markers were scored for the presence (1) and absence (0) of the corresponding band among the genotypes. Consequently, a data matrix comprising ' 1 ' and ' 0 ' was formed and subjected to further analysis. Further processing of data was done by carrying out sequential agglomerative hierarchical non-overlapping clustering (SAHN), on squared Euclidean distance matrix. Similarity matrix was done using Jaccard's coefficient, in which similarity matrices were utilized to construct the UPGMA (Unweighted Pair Group Method with Arithmetic average) dendrogram. Data analysis was done using NTSYs PC (Rohlf, 1998).

\section{RESULTS AND DISCUSSION}

The present investigation envisaged the degree of genetic diversity based on marker data in forty three genotypes of pigeonpea (Fig 1). Genetic diversity/ relatedness among the genotypes was assessed on the basis of Polymorphic information content (PIC) value. Out of 41 HASSR markers (Table 2), 21 markers (Table 3) were completely amplified and a total of 193 alleles were found. In the remaining markers, some were amplified and some were not amplified. Polymorphic information content (PIC Value) of SSR markers was calculated (Table 2). It ranged from 0.87 (HASSR 116) to 0.60 (HASSR-22, HASSR-29 and HASSR-68) with an average of 0.74 . Molecular polymorphism was $58.8 \%$ with $21 \mathrm{HASSR}$ primers indicating the low level of genetic variation among the varieties (Table 3 ). The polymorphic bands were scored visually as present (1) or absent $(0)$ on a binary matrix. Genetic similarity between the varieties was estimated using Jaccards Coefficient of similarity index. Dendrogram was performed using the Unweighted Pair Group Method with an Arithmetic mean (UPGMA) algorithm and the NTSYS software (Fig 2).

\section{Cluster analysis}

Cluster analysis of the genotypes is depicted in Fig 2. The genotypes were grouped into two main clusters i.e. cluster

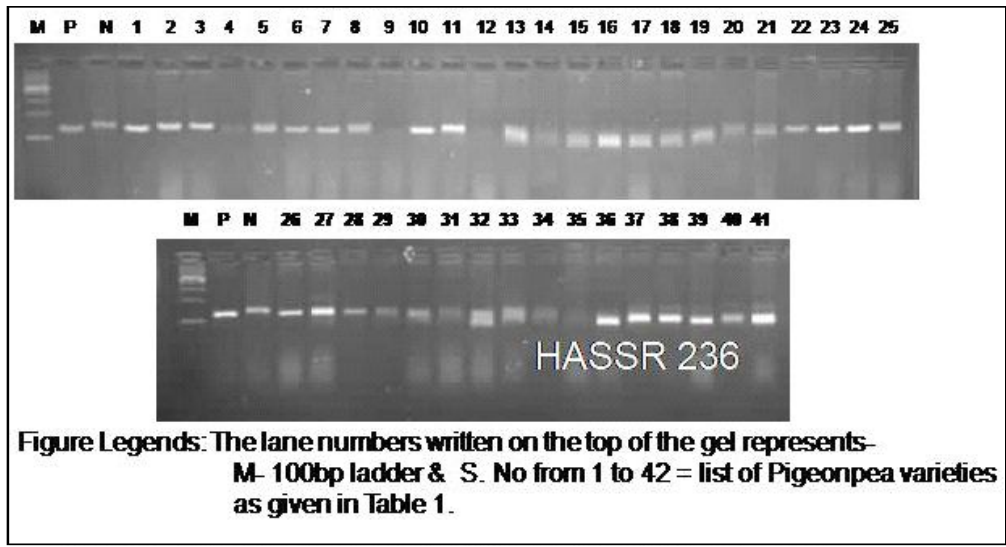

Fig 1A: SSR Amplification of 43 pigeonpea varieties with HASSR 236.

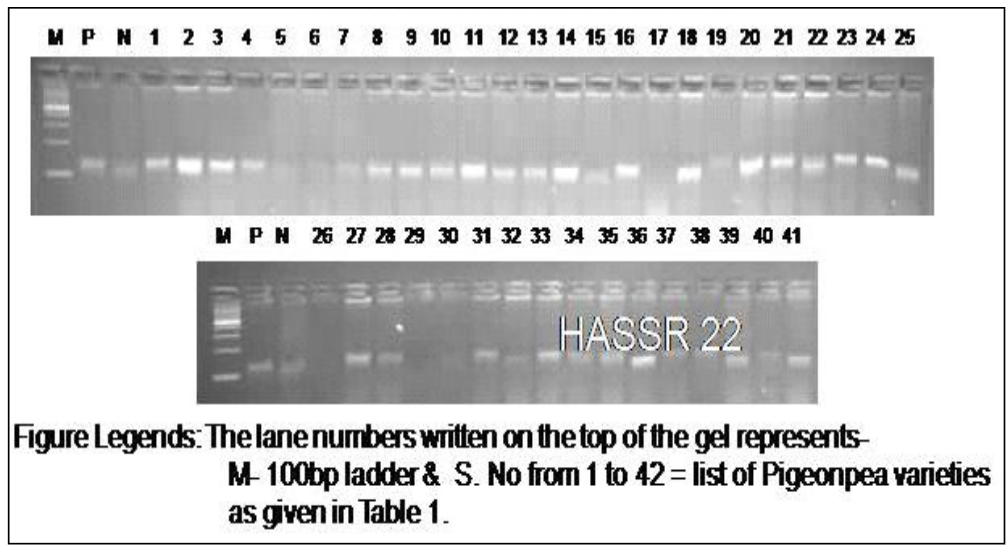

Fig 1B: SSR amplification of 43 pigeonpea varieties with HASSR 22. 
Genetic Diversity Analysis in Extra Early Pigeonpea [Cajanus cajan (L.)] Genotypes using SSR Markers

Table 2: Details of HASSR markers used for diversity analysis among 43 genotypes of pigeonpea.

\begin{tabular}{|c|c|c|c|}
\hline Primer name & Sequence of the primers $\left(5^{\prime}-3^{\prime}\right)$ & Annealing temperature $\left({ }^{\circ} \mathrm{C}\right)$ & PCR amplicon size (bp) \\
\hline HASSR1 F & ССTGTGACTCAАСTCAАTCTC & 61 & $170-190$ \\
\hline HASSR1 R & TGGAATACCGAATTAATGCTC & & \\
\hline HASSR5 F & GATAAGACCTTTTCACAAGCA & 57 & $100-130$ \\
\hline HASSR5 R & GATAAGACCTTTTCACAAGCA & & \\
\hline HASSR10 F & TTTTAACATCAAGGTTCCGTA & 58 & $150-180$ \\
\hline HASSR10 R & ААТTСТTСТАAАCATGСАССТ & & \\
\hline HASSR11 F & ATTTTGGAGGATACAGCATTT & 56 & 150 \\
\hline HASSR11 R & ACCATCACGAGTATATCTCCA & & \\
\hline HASSR21 F & GCAGGTCAGTTGCTTAACATA & 59 & $180-200$ \\
\hline HASSR21 R & AAGGCCAGAAATAACTTCTTC & & \\
\hline HASSR22 F & TCACAAACACAACACAACAAT & 59 & $120-160$ \\
\hline HASSR22 R & СTCTCTGCAGTTCTGGAATAC & & \\
\hline HASSR23 F & AAAGCTATGGAGCAATAGAAGA & 56 & $160-195$ \\
\hline HASSR23 R & TAATGGGTTGACCAGAAATTA & & \\
\hline HASSR29 F & AGAACACACAAAATGTAAAAGG & 60 & $110-190$ \\
\hline HASSR29 R & CTAGTGTATGGCATCACCATC & & \\
\hline HASSR37 F & TCAAAACTCCTCAGGTAATAAAA & 59 & $100-160$ \\
\hline HASSR37 R & ACTGCATTTAGTTTTGGACAG & & \\
\hline HASSR45 F & GGTGGAAGGAATCTTTAACTT & 57 & $160-190$ \\
\hline HASSR45 R & АCTTTCCTTTGATGCTTTTTC & & \\
\hline HASSR52 F & TCCСTTTTGAATAAAGGAGAC & 58 & $140-180$ \\
\hline HASSR52 R & TCCACACAACAAGGTTTAGAT & & \\
\hline HASSR68 F & ATCTTTTGGGTTGGTAAATTC & 56 & $170-200$ \\
\hline HASSR68 R & CGTTCTTCATCTTTTCACAAT & & \\
\hline HASSR71 F & TGTTGAAGCGAAAATAACAA & 55 & $160-190$ \\
\hline HASSR71 R & ACCGTATATTGTCCTCTGGAT & & \\
\hline HASSR86 F & GGTATTGCCTCCAAATACAAT & 57 & $120-160$ \\
\hline HASSR86 R & AAACTTCGATCAAAAGGAGAT & & \\
\hline HASSR90 F & GGGTTTATAACTTGGAAATGC & 58 & $170-190$ \\
\hline HASSR90 R & АCTTTTGTCCCATCTGTTTTC & & \\
\hline HASSR91 F & GTGACCTTTCGAGAGAAAAAT & 60 & $110-150$ \\
\hline HASSR91 R & TTAGTGGAGTGAGAGTCATGG & & \\
\hline HASSR92 F & GTGACCTTTCGAGAGAAAAAT & 60 & $150-200$ \\
\hline HASSR92 R & TTAGTGGAGTGAGAGTCATGG & & \\
\hline HASSR110 F & GTGAATTTTAGTACACAAGACAA & 58 & 180 \\
\hline HASSR110 R & AAGTGATCGAATAATGGTGTG & & \\
\hline HASSR114 F & TACTGGTGATGATTGTGACAG & 58 & $120-190$ \\
\hline HASSR114 R & ААTTCAАСТСТАACATСТTCTGA & & \\
\hline HASSR116 F & TGAGATCTGGTCAAGGGTTA & 58 & $180-190$ \\
\hline HASSR116 R & GGTTGCATCTTCTTTTCTCTT & & \\
\hline HASSR143 F & ATTGACTCAACСТСССТTTAG & 58 & $160-210$ \\
\hline HASSR143R & TTGAAGTAAATGGATCATTCC & & \\
\hline HASSR155 F & ACTTGTTGTTGACCCGACT & 58 & $150-170$ \\
\hline HASSR155 R & CTAAATAAGAGTAACAATGAGCA & & \\
\hline HASSR160 F & TGAATCACGTCTTAGATTTTAAC & 58 & $115-160$ \\
\hline HASSR160 R & TGTATTCCCAACATTATTTCG & & \\
\hline HASSR181 F & ATGACCCAACTTGACTAGGTT & 58 & $120-180$ \\
\hline HASSR181 R & ATGACCCAACTTGACTAGGTT & & \\
\hline HASSR189 F & CTTAGTGGAAGGAATTGGAGT & 58 & 200 \\
\hline HASSR189 R & TGGCATAACAGTACGGATAGTA & & \\
\hline
\end{tabular}


Genetic Diversity Analysis in Extra Early Pigeonpea [Cajanus cajan (L.)] Genotypes using SSR Markers

Table 2: Continue........

HASSR194 F

HASSR194 R

HASSR219 F

HASSR219 R

HASSR223 F

HASSR223 R

HASSR224 F

HASSR224 R

HASSR229 F

HASSR229 R

HASSR230 F

HASSR230 R

HASSR231 F

HASSR231 R

HASSR236 F

HASSR236 R

HASSR267 F

HASSR267 R

HASSR271 F

HASSR271 R

HASSR282 F

HASSR282 R

HASSR289 F

HASSR289 R

HASSR $294 \mathrm{~F}$

HASSR 294 R

HASSR303 F

HASSR 303 R

HASSR $305 \mathrm{~F}$

HASSR 305 R

HASSR $323 \mathrm{~F}$

HASSR $323 \mathrm{R}$

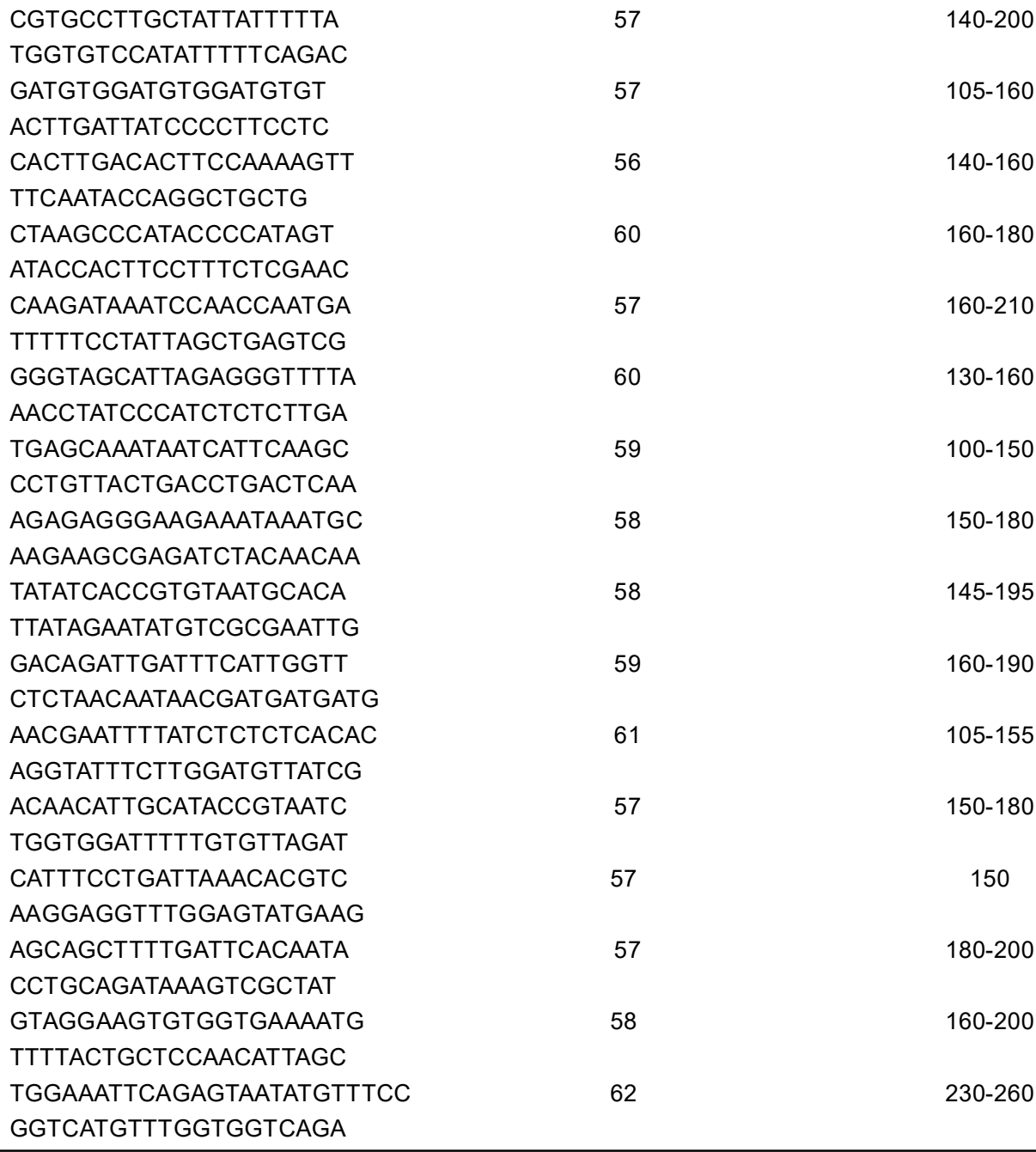

A cluster and cluster B. Cluster A consists of only one genotype viz., ICPL 87119 and it showed $28 \%$ of similarity with Cluster B. Cluster B is further divided into sub clusters i.e. sub cluster $B_{1}$ and $B_{2}$ at $30 \%$ of similarity. The sub cluster $B_{1}$ is further divided into sub cluster $B_{1.1}$ and sub cluster $B_{1.2}$ at $35 \%$ of similarity. The sub cluster $B_{1.1}$ had 5 genotypes viz., UPAS 190, ICPL 11155, ICPL11161, ICPL11151 and ICPL11156. The sub cluster $B_{1.2}$ had 32 genotypes viz., ICPL11159, ICPL10140, ICPL11100, ICPL1116, ICPL10116, ICPL11151, ICPL11158, ICPL11160, ICPL11111, ICPL11199, ICPL11106, ICPL 11174, ICPL11198, ICPL11176, ICPL11118, ICPL10118, ICPL11111, ICPL11191, ICPL 10115, ICPL11114, ICPL10111, ICPL10119, ICPL10115, ICPL11165, ICPL11154, ICPL11185, ICPL11101, ICPL87, ICPL88019 and ICPL11141, while, sub cluster B2 had 5 genotypes viz., ICPL84031, ICPL88034, ICPL161, ICPL87091 and CORG9701. In sub cluster B2, the pigeonpea genotypes ICPL 84031and ICPL 88014 showed $68 \%$ of similarity, while the pigeonpea genotypes ICPL 87091 and CORG 9701were also showed
$68 \%$ of similarity and in combination showed $50 \%$ of similarity. In Dendrogram the pigeonpea genotypes present in sub cluster B1.1 viz., ICPL 10118 and ICPL 11111 were showed highest percent $(91 \%)$ of similarity.

It is observed from the study that the genotype ICPL 87119 was found to be the most diverse as it occupied a single cluster. It is also interesting to observe that it is resistant to wilt. Hence based on cluster analysis, the identified diverse pigeonpea genotypes can be effectively selected for carrying out various breeding and crop improvement programmes. The study clearly indicated that SSR marker profiles were best-suitable for assessing genetic relationships among pigeonpea genotypes. Based on similarity coefficients and cluster analysis pigeonpea genotypes ICPL 84031, ICPL88034, ICPL161, ICPL87091 and CORG9701 were genetically more distant from other pigeonpea genotypes and these varieties can be used for their desirable characteristics in breeding programs for Pigeonpea improvement (Fig 2). 
Earlier, assessment of the genetic variation in pigeonpea has been carried out using different types of molecular markers including random amplified polymorphic DNA (RAPD) (Sarika Shende and Anand Raut; 2013), Resistance gene analog (RGA)-anchored amplified fragment length polymorphism (AFLP-RGA) (Patil et al. 2014) and simple sequence repeat (SSR) (Bohra et al. 2017, Suman et al. 2019 and Pankaj Sharma et al. 2020). Similar to our results, the narrow genetic base of the domesticated pigeonpea was also evident from analyses based on other DNA marker systems such as RAPD (Ratnaparkhe et al.1995), RFLP (Nadimpalli et al. 1993), AFLP (Panguluri et al.2006), DArT (Yang et al. 2006), ISR (Kudapa et al. 2012) and SNP (Kassa et al. 2012). As compared to the earlier successful reports, the number of polymorphic and informative markers used for genetic diversity analysis in the present investigation is more.

Table 3: List of 21 polymorphic markers with their sequence, annealing temperature and PIC.

\begin{tabular}{|c|c|c|c|c|}
\hline Primer name & Sequence of the primers $\left(5^{\prime}-3^{\prime}\right)$ & $\begin{array}{c}\text { Annealing } \\
\text { temperature }\end{array}$ & $\begin{array}{c}\text { PCR amplicon } \\
\text { size (bp) }\end{array}$ & $\begin{array}{l}\text { PIC (Polymorphic } \\
\text { information content) }\end{array}$ \\
\hline HASSR $1 \mathrm{~F}$ & СCTGTGACTCAACTCAATCTC & 61 & $170-190$ & 0.64 \\
\hline HASSR 1 R & TGGAATACCGAATTAATGCTC & & & \\
\hline HASSR $10 \mathrm{~F}$ & TTTTAACATCAAGGTTCCGTA & 58 & $150-180$ & 0.75 \\
\hline HASSR $10 \mathrm{R}$ & ААТTСТTСТАААСАТGСАССТ & & & \\
\hline HASSR $21 \mathrm{~F}$ & GCAGGTCAGTTGCTTAACATA & 59 & $180-200$ & 0.75 \\
\hline HASSR $21 \mathrm{R}$ & AAGGCCAGAAATAACTTCTTC & & & \\
\hline HASSR $22 \mathrm{~F}$ & TCACAAACACAACACAACAAT & 59 & $120-160$ & 0.60 \\
\hline HASSR $22 \mathrm{R}$ & СTCTCTGCAGTTCTGGAATAC & & & \\
\hline HASSR $29 \mathrm{~F}$ & AGAACACACAAAATGTAAAAGG & 60 & $110-190$ & 0.60 \\
\hline HASSR $29 \mathrm{R}$ & CTAGTGTATGGCATCACCATC & & & \\
\hline HASSR $45 \mathrm{~F}$ & GGTGGAAGGAATCTTTAACTT & 57 & $160-190$ & 0.70 \\
\hline HASSR $45 \mathrm{R}$ & АCTTTCCTTTGATGCTTTTTC & & & \\
\hline HASSR $52 \mathrm{~F}$ & GCGGATCGTTACACTTTTA & 58 & 200 & 0.86 \\
\hline HASSR $52 \mathrm{R}$ & AGACGTTGCTTAAGTGTCTCA & & & \\
\hline HASSR $68 \mathrm{~F}$ & ATCTTTTGGGTTGGTAAATTC & 56 & $170-200$ & 0.60 \\
\hline HASSR $68 \mathrm{R}$ & CGTTCTTCATCTTTTCACAАT & & & \\
\hline HASSR 86 F & GGTATTGCCTCCAAATACAAT & 57 & $120-160$ & 0.74 \\
\hline HASSR $86 \mathrm{R}$ & AAACTTCGATCAAAAGGAGAT & & & \\
\hline HASSR $110 \mathrm{~F}$ & GTGAATTTTAGTACACAAGACAA & 58 & 180 & 0.74 \\
\hline HASSR $110 \mathrm{R}$ & AAGTGATCGAATAATGGTGTG & & & \\
\hline HASSR 114 F & TACTGGTGATGATTGTGACAG & 58 & $120-190$ & 0.75 \\
\hline HASSR $114 \mathrm{R}$ & ААТTСААСТСТААСАТСТTСТGА & & & \\
\hline HASSR $116 \mathrm{~F}$ & TGAGATCTGGTCAAGGGTTA & 58 & $180-190$ & 0.87 \\
\hline HASSR $116 \mathrm{R}$ & GGTTGCATCTTCTTTTCTCTT & & & \\
\hline HASSR $155 \mathrm{~F}$ & ACTTGTTGTTGACCCGACT & 58 & $150-170$ & 0.84 \\
\hline HASSR $155 \mathrm{R}$ & CTAAATAAGAGTAACAATGAGCA & & & \\
\hline HASSR $181 \mathrm{~F}$ & ATGACCCAACTTGACTAGGTT & 58 & $120-180$ & 0.85 \\
\hline HASSR $181 \mathrm{R}$ & ATGACCCAACTTGACTAGGTT & & & \\
\hline HASSR $189 \mathrm{~F}$ & CTTAGTGGAAGGAATTGGAGT & 58 & 200 & 0.75 \\
\hline HASSR $189 \mathrm{R}$ & TGGCATAACAGTACGGATAGTA & & & \\
\hline HASSR $224 \mathrm{~F}$ & CTAAGCCCATACCCCATAGT & 60 & $160-180$ & 0.75 \\
\hline HASSR 224 R & ATACCACTTCCTTTCTCGAAC & & & \\
\hline HASSR $230 \mathrm{~F}$ & GGGTAGCATTAGAGGGTTTTA & 60 & $130-160$ & 0.70 \\
\hline HASSR $230 \mathrm{R}$ & ААССТАТСССАТСТСТСТTGА & & & \\
\hline HASSR 236 F & AGAGAGGGAAGAAATAAATGC & 58 & $150-180$ & 0.85 \\
\hline HASSR 236 R & AAGAAGCGAGATCTACAACAA & & & \\
\hline HASSR $289 \mathrm{~F}$ & ACAACATTGCATACCGTAATC & 57 & $150-180$ & 0.72 \\
\hline HASSR 289 R & TGGTGGATTTTTGTGTTAGAT & & & \\
\hline HASSR 294 F & CATTTCCTGATTAAACACGTC & 57 & 150 & 0.85 \\
\hline HASSR 294 R & AAGGAGGTTTGGAGTATGAAG & & & \\
\hline HASSR $303 \mathrm{~F}$ & AGCAGCTTTTGATTCACAATA & 57 & $180-200$ & 0.70 \\
\hline HASSR 303 R & CCTGCAGATAAAGTCGCTAT & & & \\
\hline
\end{tabular}




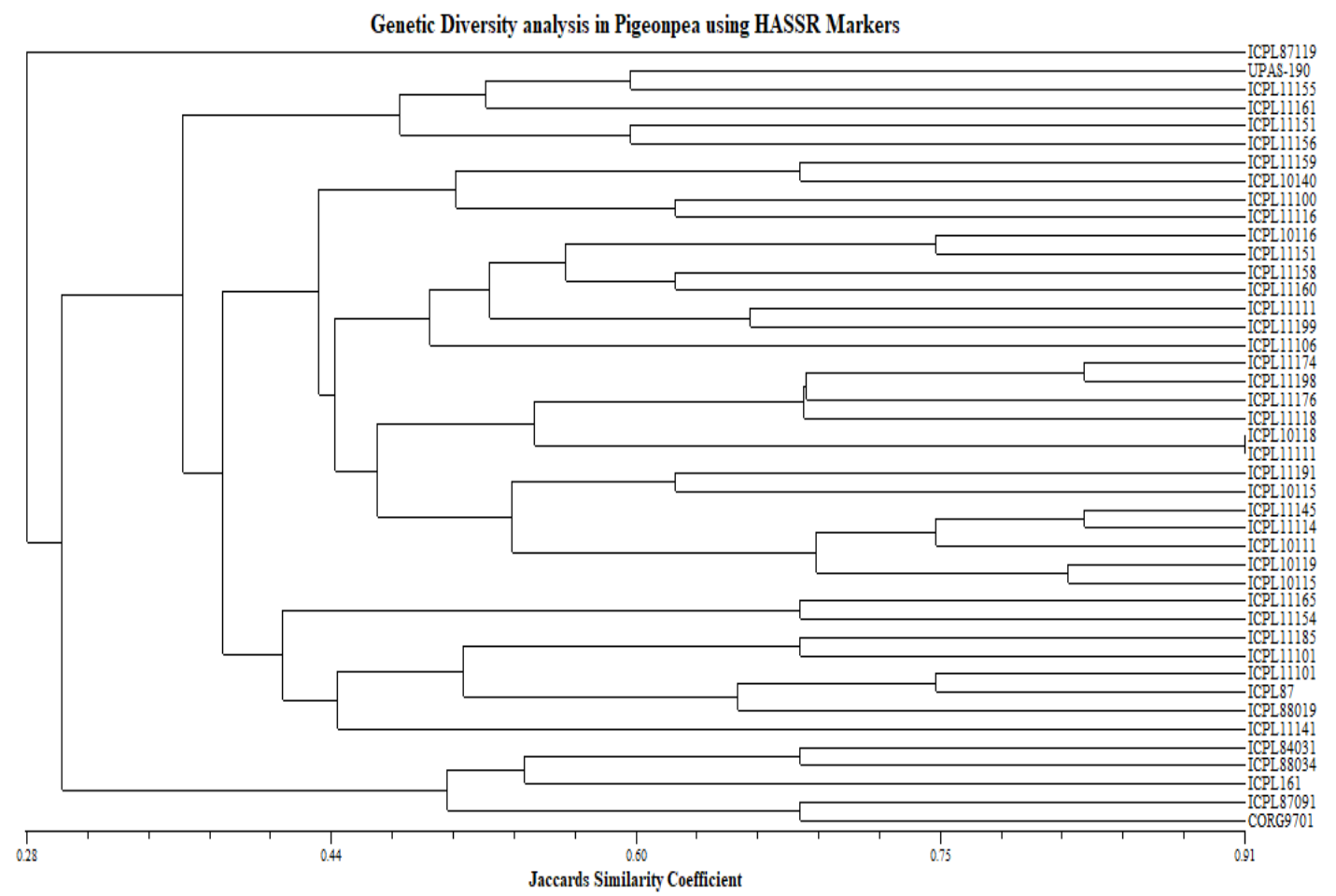

Fig 2: Cluster analysis of 43 pigeonpea genotypes based on UPGMA analysis.

\section{CONCLUSION}

In the present investigation, we have successfully assessed the levels of inter and intraspecific diversity relationships among 43 exra early pigeonpea genotypes. Pigeonpea genotype ICPL87119 is wilt resistant and also genetically more distant from other pigeonpea genotypes viz., ICPL84031, ICPL88014, ICPL161, ICPL87091 and CORG9701. Hybridization among these diverse parents may helpful to obtain better extra early genotypes with wilt resistance. Results obtained from the present investigation would be highly useful in Pigeonpea breeding programs and may be used for further crop improvement using advance marker systems.

\section{ACKNOWLEDGEMENT}

The authors gratefully acknowledge the EXTRAMURAL RESEARCH (EMR) fund of Indian Council of Agricultural Research (ICAR) for providing funding and Professor Jayashankar Telangana State Agricultural University (PJTSAU) for providing facilities to carry out the Research work and for ICRISAT for providing the material.

\section{REFERENCES}

Bohra, A., Jha, R., Pandey, G., Patil, P.G., Saxena, R.K., Singh, I.P., Singh, D., Mishra, R.K., Mishra, A., Singh, F., Varshney, R.K. and Singh, N.P. (2017). New hypervariable SSR markers for diversity analysis, hybrid purity testing and trait mapping in pigeonpea[Cajanus cajan (L.) Millspaugh] . Frontiers in Plant Science. 8: 1-15.
Gupta, P.K. and Varshney R.K. (2000). The development and use of microsatellite markers for genetic analysis and plant breeding with emphasis on bread wheat. Euphytica. 113: 163-185.

Hari, Y., Jagan Mohan Rao, P., Balakrishna, K., Thirumala Rao, V., Raghu Rami Reddy, P., Mahesh, U. (2017). Genetic diversity analysis among Yellow Mosaic Virus (YMV) resistant and susceptible varieties in mungbean (Vigna radiata L.) using SSR markers. International Journal of Agriculture Innovations and Research. 6(1): 67-72.

Kassa, M.T., Penmetsa, R.V., Carrasquilla-garcia, N., Sarma, B.K., Datta, S., Upadhyaya, H.D., Varshney, R.K., Von Wettberg Eric, J.B. and D.R. Cook, D.R. (2012). Genetic patterns of domestication in pigeonpea [Cajanus cajan (L.) Millsp.] and wild Cajanus relatives. PLoS ONE., 7- 6.

Kudapa, H., Bharti, A.K., Cannon, S.B., Farmer, A.D., Mulaosmanovic, B., Kramer, R., Bohra, A., Weeks, N.T., Crow, J.A., Tutejaa, R., Shah, T., Duta, S., Gupta, D.K., Singh, A., Gaikwad, K., Sharma, T.R., May, G.D., Singh, N.K. and R.K. (2012). A comprehensive transcriptome assembly of pigeonpea (Cajanus cajan L.) using Sanger and secondgeneration sequencing plat forms. Mol. Plant. 5: 1020-1028.

Murray, M.G. and Thompson, W.F. (1980). Nucleic Acids Research. 8(19): 4321-4325.

Nadimpalli, R.G., Jarret, J.L., Pathak, S.C. and Kochert, G. (1993). Phylogenetic relationships of pigeonpea (Cajanus cajan) based on nuclear restriction fragment length polymorphism. Genome. 36: 216-223

Patil, P.G., Datta, S., Ag, bawa, I.O., Singh, I.P., Soren, K.R., Das, A., Choudhary, A.K. and Chaturvedi, S.K. (2014). Using AFLP-RGA markers to assess genetic diversity among pigeonpea (Cajanus cajan) genotypes in relation to major diseases. Acta Botanica Brasilica. 28(2): 198-205. 
Panguluri, S.K., Janaiah, J., Govil , J.N., Kumar, P.A. and Sharma, P.C. (2006). AFLP finger printing in pigeonpea (Cajanus cajan L. Millsp.) and its wild relatives. Genetic Resources and Crop Evolution. 53: 523-531

Ratnaparkhe, M.B., Gupta, V.S., Ven Murthy, M.R. and Ranjekar, P.K. (1995). Genetic finger printing of pigeonpea [Cajanus cajan (L.) Millsp] and its wild relatives using RAPD markers. Theor Applied Gen. 91: 893-898

Rohlf, F.J. (1998). NTSYS-PC, Numerical Taxonomy and Multivariate Analysis System, version 2.0, New York: Applied Biostatistics Inc.

Sharma, P., Singh, I., Asmita, S., Singh, S. and Gaurav, K. (2020). enetic divergence studies through microsatellite markers in pigeonpea [Cajanus cajan (L.) Millsp.]. Legume Research. 43(3): 312-319.

Sarika Shende, S. and Anand, R. (2013). Analysis of genetic diversity in pigeon pea (Cajanus cajan) by using PCR based molecular marker. Recent Research in Science and Technology. 5(2): 20-23
Suman, S., Rani, B., Sharma, V.K., Kumar, H. and Shahi, V.K. (2019). SSR marker based profiling and diversity analysis of mungbean [Vigna radiata (L.) Wilczek] genotypes. Legume Research 42: 585-594

Varshney, R.K., Chen, W., Li, Y., Bharti, A.K., Saxena, R.K. and Schlueter, J.A, et al.(2012a). Draft genome sequence of pigeonpea (Cajanus cajan), an orphan legume crop of resource-poor farmers. Nature Biotechnology. 30: 83-89.

Varshney, R.K., Song, C., Saxena, R.K., Azam, S., Yu, S., Sharpe, A.G. and Cook, D.R. (2013). Draft genome sequence of chickpea (Cicer arietinum) provides a resource for trait improvement. Nature Biotechnolgy. 31: 240-248.

Yang, S., Pang, W., Harper, J., Carling, J., Wenzl, P. and Huttner, E. (2006). Low level of genetic diversity in cultivated pigeonpea compared to its wild relatives is revealed by diversity arrays technology (DArT). Theor. Applied Genet. 113: 585-595. 